\title{
30. PALEOMAGNETISM ÓF A PISTON CORE COLLECTED IN THE DAITO BASIN NEAR DEEP SEA DRILLING PROJECT SITE 446
}

\author{
Shoji Tonouchi and Kazuo Kobayashi, Ocean Research Institute, University of Tokyo
}

\section{INTRODUCTION}

A piston core with a length of 9.60 meters (KH76-2-3) was collected in the Daito Basin about $30 \mathrm{~km}$ south of DSDP Site $446\left(24^{\circ} 27.2^{\prime} \mathrm{N} ; 132^{\circ} 35.4^{\prime} \mathrm{E}\right.$ water depth $4670 \mathrm{~m}$ ) during a site-survey cruise of the R/V HakuhoMaru of the Ocean Research Institute, University of Tokyo (Figure 1). The core is mostly brown silty clay, visually similar to the uppermost Site 446 cores. Seismic-reflection profiles in this basin indicate that the sediment structure is nearly flat, and no local variations in lithology and rate of sedimentation between the DSDP site and the piston-core site are predicted.

In this article, the paleomagnetic properties of the piston core are described. Sediment age and sedimentation rate are determined by the magnetostratigraphic method, based upon magnetic-polarity boundaries found in the core. The results are compared with paleontological data for Site 446 .

\section{LITHOLOGY OF THE PISTON CORE}

Visual description of a split surface is presented in Figure 2. At depths of 20 to $23 \mathrm{~cm}$ from the top, a layer of volcanic ash is recognized. Glass shards contained in the layer are colorless and appear to represent felsic volcanism possible in the northern part of the Ryukyu arc (Furuta and Arai, 1979).

A dark-brownish-black streak roughly $6 \mathrm{~cm}$ thick is seen at a depth of about 6 meters, but its origin is unidentified. Excepting these two horizons and several very thin streaks, the piston core consists of homogeneous dark-brown to light-brown silty clay. The very sharp boundaries and approximate horizontality of the tephra layers and the streaks is evidence of sediment recovery without mechanical disturbances due to pipewall friction or mud inflow.

\section{PALEOMAGNETISM MEASUREMENT}

Contiguous cubic samples $2 \mathrm{~cm}$ on an edge were taken from the split core, and the direction and intensity of their natural remanent magnetization (n.r.m.) were measured with a spinner magnetometer.

Stepwise alternating-field (AF) demagnetization was effected in more than 20 selected samples. It was shown with this experiment that 100 oe is almost sufficient to eliminate soft components of remanent magnetization. All the specimens were then demagnetized by AF with 100-oe peak intensity. Declination, inclination, and intensity of natural remanent magnetization after demag-

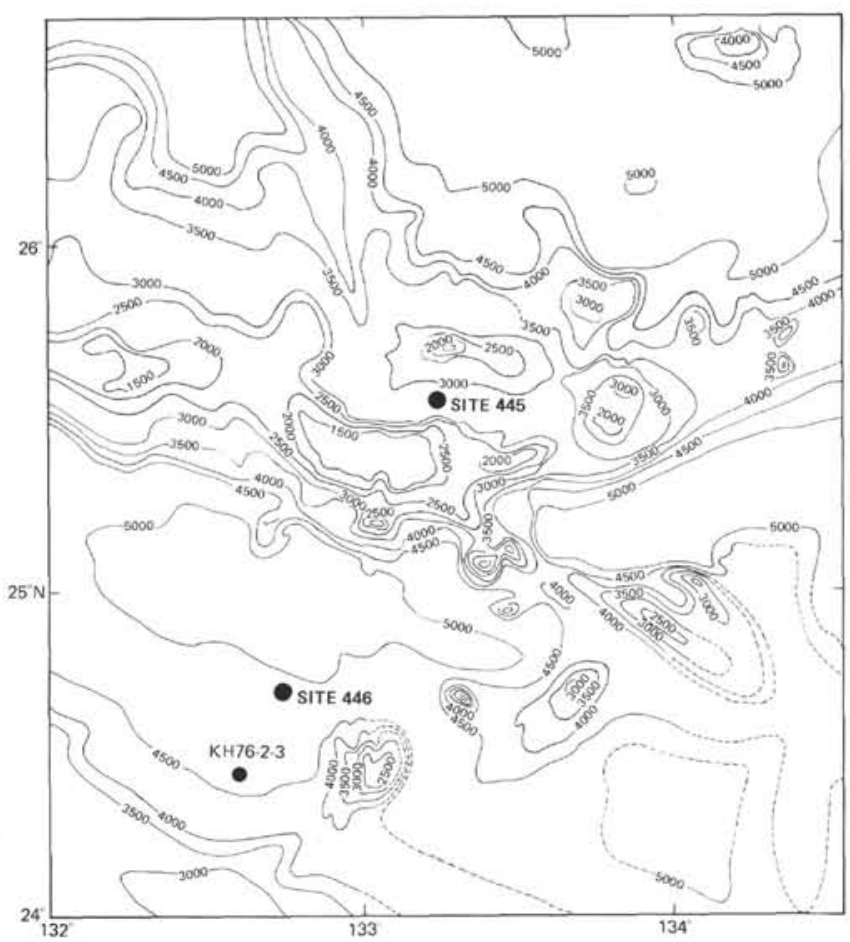

Figure 1. Locations of DSDP Sites 446 (and 445) and piston core KH76-2-3 (bathymetric contours in meters drawn by Tokuyama et al., 1979, based upon updated, available data).

netization by 100 -oe AF are shown in Figure 3. Here, declination is arbitrarily relative to the core axis. The boundary between the Brunhes and Matuyama magnetic-polarity epochs and the Jaramillo event are distinctly recognizable in declination, but they are not as clear in inclination, possible because 100 -oe AF is not quite sufficient to remove viscous magnetization completely.

Changes in normalized intensity (left) and direction (right, in stereographic projection) with AF demagnetization are shown in Figure 4. It is remarkable that intensity of samples with normal declination decreases monotonously with increasing demagnetizing field, but a peak is observed at 100 to 150 oe for samples with reversed declination.

In one sample represented in Figure 4B, inclination was reversed only after the sample was demagnetized at 150 oe. The viscous component of magnetization in this sample is more stable than that in some others. This may explain the irregularity of the inclinations corresponding to the Matuyama epoch. 


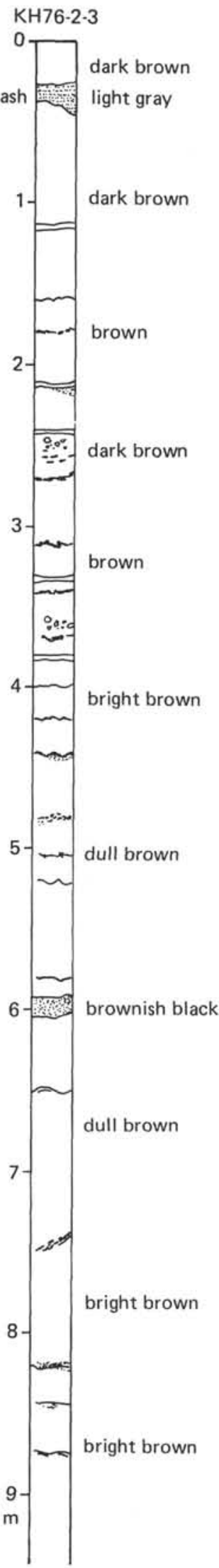

Figure 2. Visual descriptions of colors and lithologies of split surface of core KH76-2-3.
The original component of natural remanent magnetization seems to be quite stable, as the median destructive field is stronger than 300 oe for most of the samples examined. Demagnetization curves of anhysteretic remanent magnetization acquired by $\mathrm{AF}$ with a peak intensity of 800 oe (under a stationary field of 0.5 to 1.0 oe) for the same specimens (Figure 4, dashed lines) indicate that the coercivity for samples with both normal and reversed declination is nearly the same throughout the entire length of the core. The similarity of coercive force revealed by analyzing anhysteretic remanence implies uniformity in the size distribution of ferromagnetic minerals contained in the sediment from top to bottom.

\section{CONCLUSIONS}

It is concluded from these considerations that the pattern of magnetic polarities identified from paleomagnetic measurements of this core is a record of the Earth's magnetic field. At depths of 0.40 meters and 2.25 meters from the top, the intensity of n.r.m. is smaller by one order of magnitude than that in contiguous parts of the core. Although no appreciable deviation is seen in direction, such drops in intensity may be caused by short magnetic reversal events or excursion of field. As reported previously (Kobayashi et al., 1971; Sueishi et al., 1979), deep-sea sediments cannot hold a record of reversal when it is very short, owing to depositional mixing over a certain thickness. The event is recorded instead as a drop of intensity of n.r.m. caused by cancellation of remanences with opposite polarities.

The intensity drop at 0.40 meters may be a record of the Blake event $(0.11 \mathrm{Ma})$, and the drop at 2.25 meters is probably the Biwa event $(0.27 \mathrm{Ma})$, although paleontological control is needed for a reliable conclusion.

Correlation of polarity boundaries revealed by paleomagnetic measurement of core $\mathrm{KH} 76-2-3$ with the standard polarity time scale (Cox, 1969) provides information on ages and sedimentation rates at certain depths in this core. The transition between the Brunhes normal and Matuyama reversed epochs $(0.69 \mathrm{Ma})$ is at a depth of 5.65 meters. Boundaries of the Jaramillo event $(0.89$ and $0.95 \mathrm{ma}$ ) are at 7.40 and 8.20 meters. The age-depth relationship is linear, as seen in Figure 5.

Assuming that the top of the core represents the present, the sedimentation rate in the Brunhes epoch was 8.3 $\mathrm{m} / \mathrm{m} . \mathrm{y}$., and that in the late Matuyama was 9 to 11 $\mathrm{m} / \mathrm{m}$.y. Downward extrapolation of the jaramillo rate implies that the bottom of this 9.60 -meter piston core marks an age of 1.09 m.y.

Paleontological study at DSDP Site 446 indicates that the top of the recovered sediment (Core 446-1) is Pliocene. It is likely that about 20 meters of sediment below the mudline was lost in drilling, because it is very soft. The sedimentation rate in the Pliocene layer (Site 446 report, this volume) was about $4 \mathrm{~m} / \mathrm{m}$.y., which is not quite half the Quaternary rate. An increase in sedimentation rate during the Quaternary may have been due partly to greater volcanic activity at island arcs west of the site. 


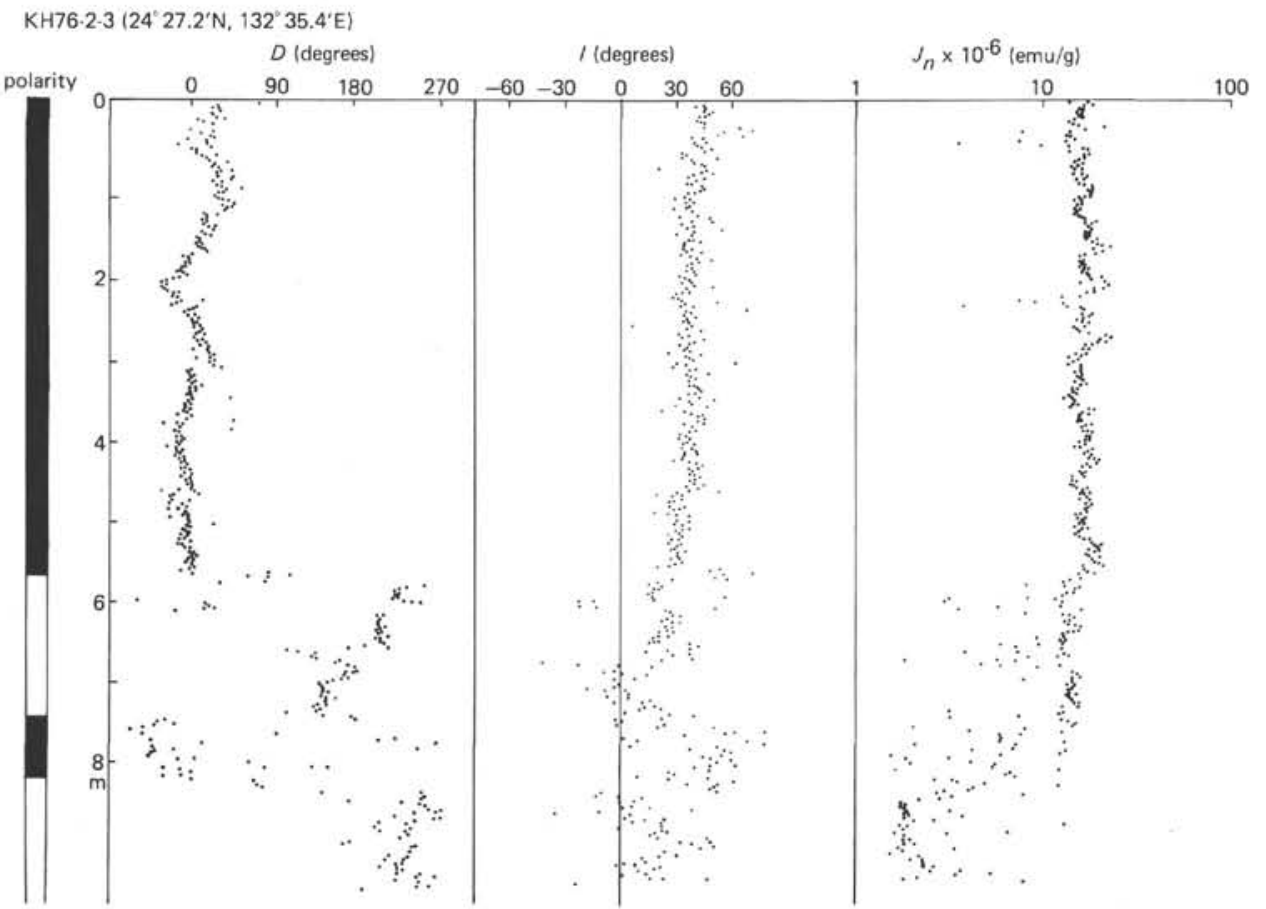

Figure 3. Declination (D), inclination (I), and intensity $\left(J_{n}\right)$ of natural remanent magnetization of core KH76-2-3 after 100-oe AF demagnetization. Scale for $J_{n}$ is logarithmic.

\section{ACKNOWLEDGMENT}

We are grateful to Drs. T. Ishii and T. Furuta, Ocean Research Institute, for reviewing this paper and great help in analysis of this piston core. We acknowledge the scientific staff and crew of the KH76-2 cruise of the R/V Hakuho-Maru for their assistance during the coring operation at sea.

\section{REFERENCES}

Cox, A., 1969. Geomagnetic reversals. Science, v. 163, pp. 237-245.

Kobayashi, K., Kitazawa, K., Kanaya, T., and Sakai, T., 1971. Magnetic and micropaleontological study of deep-sea sediments from the west-central equatorial Pacific. DeepSea Res., v. 18, pp. 1045-1057.

Sueishi, T., Sato, T., Kawai, N., and Kobayashi, K., 1979. Short geomagnetic episodes in the Matuyama epoch. Phys. Earth Planet. Int., v. 19, pp. 1-12. 

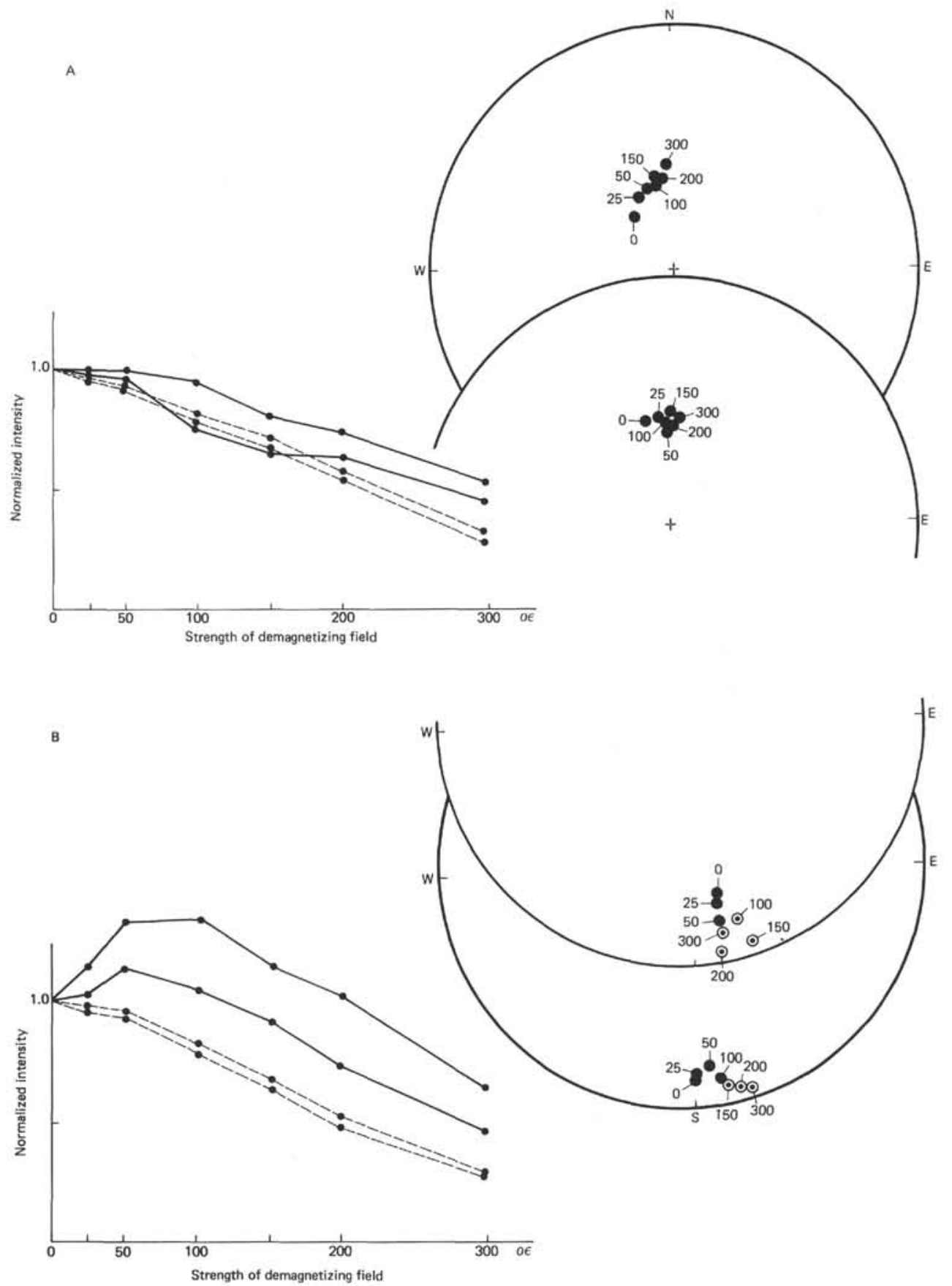

Figure 4. Changes in intensity and direction of natural remanent magnetization in four selected samples, two with normal declination $(A)$ and two with reverse declination (B). (Comparative curves for anhysteretic remanent magnetization dashed; see text.) Intensity is normalized with respect to the original. Direction is plotted in stereographic projection. Solid circles denote positive (downward) inclination and open circles denote negative (upward) inclination. Numbers beside the circles indicate strength of the demagnetizing field. 


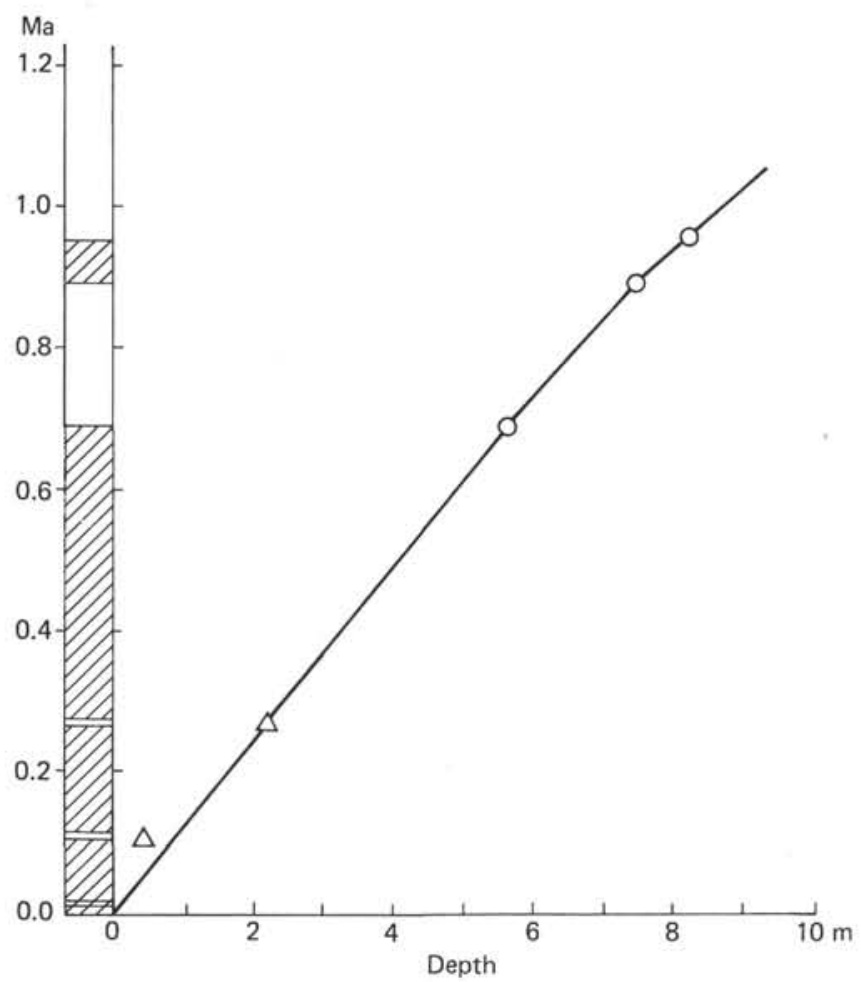

Figure 5. Depth-time relationships of polarity boundaries. Triangles indicate probable depths of short events inferred from intensity drops. 